\title{
Household food security and infant feeding practices in rural Bangladesh
}

\author{
Aatekah Owais ${ }^{1}$, David G Kleinbaum², Parminder S Suchdev ${ }^{3}$, ASG Faruque ${ }^{4}$, \\ Sumon K Das ${ }^{4}$, Benjamin Schwartz ${ }^{5}$ and Aryeh D Stein ${ }^{2,3, *}$ \\ 'Department of Epidemiology, Rollins School of Public Health and Laney Graduate School, Emory University, \\ Atlanta, GA, USA: ${ }^{2}$ Department of Epidemiology, Emory University, Atlanta, GA, USA: ${ }^{3}$ Hubert Department of \\ Global Health, Emory University, Rollins School of Public Health, 1518 Clifton Road NE, Room 7007, Atlanta, GA \\ 30322, USA: ${ }^{4}$ International Centre for Diarrhoeal Disease Research, Bangladesh (icddr,b), Dhaka, Bangladesh: \\ ${ }^{5}$ Los Angeles County Department of Public Health, Los Angeles, CA, USA
}

Submitted 11 November 2014: Final revision received 31 August 2015: Accepted 7 October 2015: First published online 13 November 2015

\begin{abstract}
Objective: To determine the association between household food security and infant complementary feeding practices in rural Bangladesh.

Design: Prospective, cohort study using structured home interviews during pregnancy and 3 and 9 months after delivery. We used two indicators of household food security at 3-months' follow-up: maternal Food Composition Score (FCS), calculated via the World Food Programme method, and an HHFS index created from an eleven-item food security questionnaire. Infant feeding practices were characterized using WHO definitions.

Setting: Two rural sub-districts of Kishoreganj, Bangladesh.

Subjects: Mother-child dyads ( $n$ 2073) who completed the 9-months' follow-up. Results: Complementary feeding was initiated at age $\leq 4$ months for $7 \%$, at 5-6 months for $49 \%$ and at $\geq 7$ months for $44 \%$ of infants. Based on 24 h dietary recall, $98 \%$ of infants were still breast-feeding at age 9 months, and $16 \%$ received $\geq 4$ food groups and $\geq 4$ meals (minimally acceptable diet) in addition to breast milk. Mothers' diet was more diverse than infants'. The odds of receiving a minimally acceptable diet for infants living in most food-secure households were three times those for infants living in least food-secure households (adjusted $\mathrm{OR}=3 \cdot 0 ; 95 \% \mathrm{CI} 2 \cdot 1,4 \cdot 3$ ). Socio-economic status, maternal age, literacy, parity and infant sex were not associated with infant diet.

Conclusions: HHFS and maternal FCS were significant predictors of subsequent infant feeding practices. Nevertheless, even the more food-secure households had poor infant diet. Interventions aimed at improving infant nutritional status need to focus on both complementary food provision and education.
\end{abstract}

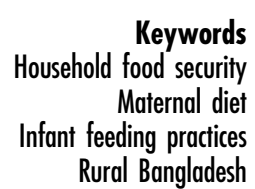

Infant and young child feeding practices are important determinants of nutritional status of children. The WHO recommends exclusive breast-feeding (defined as no other foods or drinks except for medicines and/or nutritional supplements) for the first 6 months of life. Even though the benefits of exclusive breast-feeding are well established, only $39 \%$ of infants less than 6 months old are exclusively breast-fed worldwide ${ }^{(1)}$.

The second component of infant and young child feeding is appropriate introduction of complementary foods ${ }^{(2)}$. Timely and adequate introduction of complementary feeding is essential in preventing infant undernutrition $^{(3)}$. The WHO recommends introduction of complementary foods from 6 months of age, with continued breast-feeding until the child is 2 years of age ${ }^{(2)}$.
A range of nutrient- and energy-dense complementary foods should be given frequently to cover the higher nutritional requirements for growing children. However, as with exclusive breast-feeding, complementary feeding practices are also inadequate worldwide, with complementary foods often introduced too early or too late ${ }^{(4)}$. Even when they are introduced at the right age, they may be nutritionally inadequate and unsafe ${ }^{(4)}$. Suboptimal feeding practices can result in inadequate energy consumption, as well as increased incidence of infant illnesses such as diarrhoea and respiratory infections ${ }^{(5)}$, leading to increased infant mortality and morbidity ${ }^{(6)}$.

Bangladesh is one of the twenty countries where $80 \%$ of the world's undernourished children live ${ }^{(7)}$. The prevalence of pre-school children with height-for-age, 
weight-for-age and weight-for-height $Z$-scores less than $-2 \cdot 0$ is estimated to be $41 \%, 36 \%$ and $16 \%$, respectively ${ }^{(8)}$. This high burden of childhood undernutrition occurs concurrently with a high prevalence of inadequate infant feeding practices in the country. Only $64 \%$ of infants $<6$ months of age are exclusively breast-fed, even though $100 \%$ are put to the breast at least once during this time ${ }^{(8)}$. Suboptimal feeding practices continue as the child grows older, as complementary feeding is delayed for $33 \%$ of infants 6-9 months of age ${ }^{(8)}$. Furthermore, exclusive breast-feeding prevalence has not improved over the past decade ${ }^{(8)}$. Even for those infants for whom complementary feeding is initiated in a timely manner, the diet may not be nutritionally adequate, with less than half the children between the ages of 6 and 23 months receiving a minimally acceptable diet as defined by the $\mathrm{WHO}^{(9)}$. Among children aged 6-11 months, only $18 \%$ receive a minimally acceptable $\operatorname{diet}^{(9)}$.

Household food security, defined as including both physical and economic access to food that meets people's dietary needs as well as their food preferences ${ }^{(10)}$, has been identified as an important underlying cause of childhood undernutrition $^{(11,12)}$. However, how household food security impacts infant and young child feeding practices is less well understood.

The relationship between household food security, diet and nutritional status of adults and older children is well established $^{(13-17)}$. Substantial research has also been conducted on identifying the predictors of nutritional status of infants and young children ${ }^{(11,12)}$. And it is no surprise that suboptimal complementary feeding practices are highly predictive of childhood undernutrition ${ }^{(18)}$. However, fewer studies have attempted to assess the relationship between how food secure a household is and the quality of an infant's diet. This relationship can have implications for infant nutrition intervention programmes, such as whether the appropriate intervention is to identify vulnerable children in a community or improve household food security in general.

Presumably more food-secure households are more likely to have improved infant diet. However, according to the 2011 Bangladesh Demographic and Health Survey, only $31 \%$ of children from the wealthiest, and probably the most foodsecure quintile in the country were receiving a minimally acceptable diet ${ }^{(8)}$. The figure was $11 \%$ for children from the lowest quintile ${ }^{(8)}$. Therefore, the aim of the present study was to determine the strength of the association between household food security and infant feeding practices independent of other sociodemographic factors in the context of a food-insecure population in rural Bangladesh.

\section{Methods}

\section{Study population and setting}

The study setting, population and data collection tools have been described in detail elsewhere ${ }^{(19,20)}$. Briefly, data for the study were collected in the context of evaluation of Window of Opportunity, a community-based nutrition and infant and young child feeding programme implemented by CARE in six countries, including Bangladesh, where it was known as Akboni Shomay. Akboni Shomay was carried out in Karimganj. A rural sub-district of Kishoreganj with a population of $\sim 320000$, approximately $120 \mathrm{~km}$ north of Dhaka, this is one of the most food-insecure regions in Bangladesh.

An integrated set of individual-, household- and community-level interventions was implemented. Women living in a second sub-district, Katiadi, served as controls. To evaluate the programme, a prospective cohort of $\sim 2400$ pregnant women (1200 per sub-district) was recruited between January and October 2011. Pregnant women were recruited in their seventh month of gestation, with follow-up of their offspring scheduled to occur at 3, 9, 16 and 24 months of age.

\section{Variable derivation}

To evaluate infant diet quality, our main outcome, we used two indicators developed by the WHO. The first, infant dietary diversity, is defined as number of food groups consumed by the infant in the past $24 \mathrm{~h}^{(21)}$. Using maternal recall at the 9-months' follow-up, everything the child ate over the past $24 \mathrm{~h}$ was categorized into one of seven food groups. An infant who consumes $\geq 4$ food groups is said to meet WHO's minimum dietary diversity criteria $^{(21)}$. The second index was whether a child received a minimally acceptable diet in the past $24 \mathrm{~h}^{(21)}$. This indicator is derived from the number of food groups as well as the number of meals consumed over a $24 \mathrm{~h}$ period, assessed at the 9-months' follow-up. Furthermore, whether an infant receives a minimally acceptable diet or not is also determined by his or her age and breast-feeding status. A 9-month-old breast-fed infant should receive $\geq 4$ food groups and $\geq 4$ meals over $24 \mathrm{~h}$ to be considered as having received a minimally acceptable diet.

Household food security, our main exposure, was assessed via the Food Composition Score (FCS) based on reported maternal diet at the 3-months' follow-up. Developed by the World Food Programme, FCS is a composite of dietary diversity, frequency with which food is consumed in the household and the nutritional importance of food ${ }^{(22)}$. There are seven food groups included in calculating the FCS, which is calculated by multiplying a food group-specific weighting factor with the number of days that food group was consumed over the past $7 \mathrm{~d}$ and then summed up. Animal-source protein and dairy products are assigned the largest weighting factor followed by legumes, grains, fruits and vegetables, and sugars and oil.

We also used a scale developed specifically for rural Bangladesh by Frongillo et $a l^{(23)}$. This questionnaire (called the 'HHFS questionnaire' henceforth) grades food insecurity based on frequency of food purchases, cooking and meals consumed, as well management strategies. 
The HHFS questionnaire was administered at the 3-months' follow-up. Of the eleven items included in the questionnaire, ten were used to create the HHFS score.

Information on sociodemographic variables, including household socio-economic status, maternal age, literacy and parity, were abstracted from the questionnaire administered at recruitment into the study at gestational age 7 months.

\section{Statistical analysis}

Data were imported into the statistical software package SAS version 9.3 for analysis. Median (range) was calculated for continuous variable and frequencies and percentages were calculated for categorical variables. Differences between maternal and infant diet were tested using Fisher's exact test. Household socio-economic status was assessed through residence characteristics and ownership of assets. Principal component analysis was used to create an assetbased socio-economic status score using methods described by Filmer and Pritchett ${ }^{(24)}$

Binary variables for infant dietary diversity and receipt of a minimally acceptable diet were created using WHO cut-offs $^{(21)}$. Quartiles were created for both measures of household food security for analysis. Multivariable logistic regression, adjusted for socio-economic status, maternal age, literacy and parity and infant sex, was used to determine the association between household food security and quality of infant diet. Interactions between both measures of household food security and each of the covariates were assessed. Statistical significance was set at $P<0 \cdot 05$.

\section{Results}

The 9-months' follow-up was completed by 2073 out of 2400 mother-child dyads. Based on maternal recall, complementary feeding was initiated at $\leq 4$ months for $7 \%$, at 5-6 months for $49 \%$ and at $\geq 7$ months for $44 \%$ of infants in our cohort. At the time of the 3-months' follow-up, all infants were breast-fed and $45.2 \%$ had received nothing but breast milk in the past $24 \mathrm{~h}^{(20)}$. At age 9 months, complementary feeding had been initiated for all but three infants in our cohort, with $98 \%$ also continuing to be breast-fed. The most common food groups included in infants' diet were grains, roots and tubers (93\%), non vitamin A-rich fruits and vegetables (43\%) and flesh foods (33\%). Dairy products, legumes and nuts, eggs

Table 1 Maternal characteristics* and infant feeding practices† among 2073 mother-child dyads in 2011-2012 in Kishoreganj, Bangladesh, by maternal Food Consumption Score (FCS)

\begin{tabular}{|c|c|c|c|c|c|}
\hline & \multicolumn{5}{|c|}{ Maternal FCS $\ddagger$} \\
\hline & $\begin{array}{c}19.5-54.5 \\
(n 531)\end{array}$ & $\begin{array}{c}55-61.5 \\
(n \text { 497) }\end{array}$ & $\begin{array}{c}62-76 \\
(n 525)\end{array}$ & $\begin{array}{c}76 \cdot 5-112 \\
(n 520)\end{array}$ & $P$ \\
\hline \multicolumn{6}{|l|}{ Maternal characteristics } \\
\hline Age (years), median & 25 & 24 & 24 & 24 & 0.53 \\
\hline Range & $15-49$ & $16-45$ & $15-47$ & $14-46$ & \\
\hline Literacy (\%) & & & & & 0.41 \\
\hline Cannot read at all & $37 \cdot 3$ & 31.6 & $36 \cdot 0$ & 35.6 & \\
\hline Can read part of a sentence & 14.5 & $17 \cdot 7$ & 13.9 & $16 \cdot 3$ & \\
\hline Can read a complete sentence & $48 \cdot 2$ & $50 \cdot 7$ & $50 \cdot 1$ & $48 \cdot 1$ & \\
\hline Parity (\%) & & & & & 0.85 \\
\hline 1 & $25 \cdot 8$ & $27 \cdot 4$ & $29 \cdot 7$ & $28 \cdot 1$ & \\
\hline 2 & $24 \cdot 1$ & 23.5 & $24 \cdot 0$ & $24 \cdot 8$ & \\
\hline$\geq 3$ & $50 \cdot 1$ & $49 \cdot 1$ & $46 \cdot 3$ & $47 \cdot 1$ & \\
\hline Socio-economic status (\%) & & & & & 0.24 \\
\hline 1st quintile (lowest) & 23.0 & $16 \cdot 5$ & 20.4 & $18 \cdot 7$ & \\
\hline 2nd quintile & $19 \cdot 2$ & 18.9 & $20 \cdot 2$ & $21 \cdot 3$ & \\
\hline 3rd quintile & $18 \cdot \overline{8}$ & 21.5 & 20.2 & $19 \cdot 4$ & \\
\hline 4th quintile & $19 \cdot 8$ & 23.9 & $17 \cdot 7$ & $18 \cdot 8$ & \\
\hline 5th quintile (highest) & $19 \cdot 2$ & $19 \cdot 1$ & 21.5 & $21 \cdot 7$ & \\
\hline \multicolumn{6}{|l|}{ Infant feeding practices } \\
\hline Continued breast-feeding at 9 months (\%) & 97.4 & 98.8 & 98.3 & $96 \cdot 7$ & 0.11 \\
\hline Age at complementary feeding initiation (\%) & & & & & 0.06 \\
\hline$\leq 4$ months & $5 \cdot 3$ & $5 \cdot 0$ & 4.8 & $2 \cdot 3$ & \\
\hline$\overline{5}-6$ months & 48.4 & $52 \cdot 1$ & $47 \cdot 2$ & $54 \cdot 2$ & \\
\hline$\geq 7$ months & $46 \cdot 3$ & $42 \cdot 9$ & 48.0 & 43.5 & \\
\hline \multicolumn{6}{|l|}{ Infant diet over past $24 \mathrm{~h}(\%)$} \\
\hline$\geq 4$ meals & 67.6 & 74.4 & 77.9 & 78.1 & $<0.01$ \\
\hline$>4$ food groups & 10.4 & $16 \cdot 1$ & $17 \cdot 7$ & $21 \cdot 3$ & $<0.01$ \\
\hline Minimally acceptable diet§ & $10 \cdot 4$ & $16 \cdot 1$ & $17 \cdot 3$ & $20 \cdot 6$ & $<0.01$ \\
\hline
\end{tabular}

${ }^{*}$ Assessed at baseline.

†Assessed at infant age 9 months.

$\ddagger$ Assessed via the World Food Programme method; categories are quartiles.

$\S$ Defined as $\geq 4$ meals and $\geq 4$ food groups. 
Table 2 Maternal characteristics* and infant feeding practices† among 2073 mother-child dyads in 2011-2012 in Kishoreganj, Bangladesh, by household food security (HHFS) score

\begin{tabular}{|c|c|c|c|c|c|}
\hline & \multicolumn{5}{|c|}{ HHFS score $\ddagger$} \\
\hline & $\begin{array}{l}23-37 \\
(n 407)\end{array}$ & $\begin{array}{c}38-40 \\
(n 789)\end{array}$ & $\begin{array}{c}41-41 \\
(n 368)\end{array}$ & $\begin{array}{c}42-45 \\
(n 509)\end{array}$ & $P$ \\
\hline \multicolumn{6}{|l|}{ Maternal characteristics } \\
\hline Age (years), median & 24 & 24 & 24 & 24 & 0.78 \\
\hline Range & $15-43$ & $14-45$ & $15-41$ & $15-49$ & \\
\hline Literacy (\%) & & & & & 0.71 \\
\hline Cannot read at all & 33.7 & 35.5 & $36 \cdot 7$ & 34.8 & \\
\hline Can read part of a sentence & $18 \cdot 4$ & $15 \cdot 3$ & 14.4 & 14.5 & \\
\hline Can read a complete sentence & 47.9 & $49 \cdot 2$ & 48.9 & $50 \cdot 7$ & \\
\hline Parity $(\%)$ & & & & & 0.29 \\
\hline 1 & 29.7 & $27 \cdot 2$ & 28.0 & $26 \cdot 7$ & \\
\hline 2 & $20 \cdot 4$ & $26 \cdot 9$ & 23.6 & 23.2 & \\
\hline$\geq 3$ & 49.9 & $45 \cdot 9$ & 48.4 & $50 \cdot 1$ & \\
\hline Socio-economic status (\%) & & & & & 0.65 \\
\hline 1st quintile (lowest) & $22 \cdot 1$ & 19.9 & $19 \cdot 6$ & 17.5 & \\
\hline 2nd quintile & 21.6 & $20 \cdot 0$ & $19 \cdot 6$ & $18 \cdot 7$ & \\
\hline 3rd quintile & $17 \cdot 4$ & $20 \cdot 9$ & $18 \cdot 7$ & 21.4 & \\
\hline 4th quintile & 19.9 & 19.6 & $22 \cdot 0$ & $19 \cdot 3$ & \\
\hline 5th quintile (highest) & 18.9 & 19.5 & $20 \cdot 1$ & $23 \cdot 2$ & \\
\hline \multicolumn{6}{|l|}{ Infant feeding practices } \\
\hline Continued breast-feeding at 9 months (\%) & $97 \cdot 5$ & $98 \cdot 0$ & $98 \cdot 1$ & $97 \cdot 4$ & 0.88 \\
\hline Age at complementary feeding initiation (\%) & & & & & 0.08 \\
\hline$\leq 4$ months & 6.6 & 3.9 & 3.3 & 3.9 & \\
\hline $5-6$ months & $45 \cdot 2$ & $52 \cdot 6$ & $52 \cdot 7$ & 49.7 & \\
\hline$\geq 7$ months & 48.2 & 43.5 & $44 \cdot 0$ & $46 \cdot 4$ & \\
\hline \multicolumn{6}{|l|}{ Infant diet over past $24 \mathrm{~h}(\%)$} \\
\hline$\geq 4$ meals & $62 \cdot 9$ & 73.0 & $79 \cdot 1$ & $82 \cdot 7$ & $<0.01$ \\
\hline$\geq 4$ food groups & $6 \cdot 4$ & $14 \cdot 4$ & $20 \cdot 4$ & $24 \cdot 4$ & $<0.01$ \\
\hline Minimally acceptable diet§ & $6 \cdot 4$ & $14 \cdot 1$ & $20 \cdot 4$ & 23.8 & $<0.01$ \\
\hline
\end{tabular}

${ }^{\star}$ Assessed at baseline.

†Assessed at infant age 9 months.

$\mp$ Calculated using the eleven-item HHFS questionnaire; categories are quartiles.

$\S$ Defined as $\geq 4$ meals and $\geq 4$ food groups.

and vitamin A-rich fruits and vegetables were consumed by $20 \%, 17 \%, 11 \%$ and $11 \%$ of infants, respectively.

Although $74 \%$ of infants in the study received at least four meals over a $24 \mathrm{~h}$ period, only $16 \%$ of infants in the study met the minimal dietary diversity criteria and hence were categorized as receiving a minimally acceptable diet over a $24 \mathrm{~h}$ period. The median maternal FCS assessed at the 3-months' follow-up was 62 (range: 19.5-112) and the median HHFS score was 40 (range: 23-45). Pearson's correlation estimate between the two scores was $0 \cdot 38$.

Characteristics of study households stratified by maternal diet and household food security scores are summarized in Tables 1 and 2, respectively. Maternal age, literacy and parity were similar across food security groups. Infant age at complementary feeding initiation and rates of continued breast-feeding were also similar across groups. However, infant diet quality was strongly associated with household food security status. Infants living in more food-secure households (as measured via maternal diet) were more likely to receive a minimally acceptable diet at 9 months, compared with those living in less food-secure households (adjusted OR $=3 \cdot 0 ; 95 \%$ CI 2.1, 4.3; Table 3). Results were similar using the HHFS score (Table 3). Household socio-economic status, maternal age and literacy and infant sex were not associated with infant feeding practices.

We tested for interaction between both measures of household food security and each of the covariates. There were no significant interactions for two of the three indicators of infant feeding practices: $\geq 4$ food groups and minimally acceptable diet. The relationship between household food security and $\geq 4$ meals was modified by maternal parity (maternal FCS: $P$-interaction $=0 \cdot 02$; HHFS score: $P$-interaction $=0 \cdot 048$ ).

We also examined differences between the maternal and infant diets. Table 4 summarizes the comparison of maternal and infant dietary diversity. The greatest overlap occurred for grains, roots and tubers, which $93 \%$ of mother-child dyads reported consuming over the past $24 \mathrm{~h}$. The highest discrepancy between maternal and infant diets was for flesh foods, with $63 \%$ of mothers reporting consuming meat when their infant did not, followed by non vitamin A-rich fruits and vegetables (49\%) and legumes and nuts (26\%). More than three-quarters of mother-child dyads included in the study reported not consuming eggs $(78.7 \%)$ and vitamin A-rich fruits and vegetables $(75.3 \%)$. More than half of the respondents also reported not consuming dairy products $(62.7 \%)$ and 
Table 3 Association between household food security and infant feeding practices among 2073 mother-child dyads in 2011-2012 in Kishoreganj, Bangladesh

\begin{tabular}{|c|c|c|c|c|c|c|c|}
\hline & \multicolumn{7}{|c|}{ Maternal FCS* } \\
\hline & \multirow[t]{2}{*}{$19 \cdot 5-54 \cdot 5$} & \multicolumn{2}{|c|}{$55-61 \cdot 5$} & \multicolumn{2}{|c|}{$62-76$} & \multicolumn{2}{|c|}{$76 \cdot 5-112$} \\
\hline & & OR & $95 \% \mathrm{Cl}$ & OR & $95 \% \mathrm{Cl}$ & OR & $95 \% \mathrm{Cl}$ \\
\hline \multicolumn{8}{|c|}{$\begin{array}{l}\text { Infant diet over last } 24 \mathrm{~h} \dagger \\
>4 \text { meals }\end{array}$} \\
\hline Unadjusted & Ref. & 1.3 & $1.1,1.8$ & 1.9 & $1 \cdot 3,2 \cdot 2$ & 1.7 & $1 \cdot 3,2 \cdot 2$ \\
\hline Adjusted $\ddagger$ & Ref. & $2 \cdot 2$ & $1 \cdot 3,3 \cdot 8$ & 3.0 & $1 \cdot 8,5 \cdot 0$ & $2 \cdot 7$ & $1 \cdot 6,2 \cdot 7$ \\
\hline \multicolumn{8}{|l|}{$\geq 4$ food groups } \\
\hline Unadjusted & Ref. & 1.7 & $1 \cdot 2,2 \cdot 4$ & $1 \cdot 9$ & $1 \cdot 3,2 \cdot 7$ & $2 \cdot 3$ & $1 \cdot 7,3 \cdot 3$ \\
\hline Adjusted§ & Ref. & 1.6 & $1 \cdot 1,2 \cdot 3$ & $2 \cdot 2$ & $1.5,3.2$ & 3.2 & $2 \cdot 2,4 \cdot 6$ \\
\hline \multicolumn{8}{|c|}{ Minimally acceptable dietll } \\
\hline \multirow{5}{*}{ Adjusted§ } & Ref. & 1.7 & $1 \cdot 2,2 \cdot 4$ & 1.8 & $1 \cdot 3,2 \cdot 6$ & $2 \cdot 2$ & $1 \cdot 6,3 \cdot 2$ \\
\hline & Ref. & 1.6 & $1 \cdot 1,2 \cdot 3$ & $2 \cdot 1$ & $1.5,3 \cdot 1$ & 3.0 & $2 \cdot 1,4 \cdot 3$ \\
\hline & \multicolumn{7}{|c|}{ HHFS score* } \\
\hline & \multirow[t]{2}{*}{$23-37$} & \multicolumn{2}{|c|}{$38-40$} & \multicolumn{2}{|c|}{$41-41$} & \multicolumn{2}{|c|}{$42-45$} \\
\hline & & OR & $95 \% \mathrm{Cl}$ & OR & $95 \% \mathrm{Cl}$ & OR & $95 \% \mathrm{Cl}$ \\
\hline \multicolumn{8}{|c|}{$\begin{array}{l}\text { Infant diet over last } 24 \mathrm{~h} \dagger \\
\quad \geq 4 \text { meals }\end{array}$} \\
\hline Unadjusted & Ref. & 1.6 & $1 \cdot 2,2 \cdot 1$ & $2 \cdot 2$ & $1 \cdot 6,3 \cdot 1$ & $2 \cdot 8$ & $2 \cdot 1,3 \cdot 8$ \\
\hline Adjusted $\ddagger$ & Ref. & 1.7 & $1 \cdot 2,2 \cdot 3$ & 2.5 & $1.6,3.9$ & 3.7 & $2 \cdot 1,6 \cdot 5$ \\
\hline \multicolumn{8}{|l|}{$\geq 4$ food groups } \\
\hline Unadjusted & Ref. & 2.5 & $1.6,3.9$ & 3.8 & $2 \cdot 3,6 \cdot 0$ & 4.7 & $3 \cdot 0,7 \cdot 4$ \\
\hline Adjusted§ & Ref. & $2 \cdot 1$ & $1 \cdot 3,3 \cdot 3$ & 3.0 & $1 \cdot 8,4 \cdot 8$ & 3.6 & $2 \cdot 3,5 \cdot 8$ \\
\hline \multicolumn{8}{|c|}{ Minimally acceptable dietll } \\
\hline Unadjusted & Ref. & $2 \cdot 4$ & $1.5,3.7$ & 3.8 & $2 \cdot 3,6 \cdot 0$ & 4.6 & $2 \cdot 9,7 \cdot 1$ \\
\hline Adjusted§ & Ref. & $2 \cdot 0$ & $1 \cdot 3,3 \cdot 2$ & $2 \cdot 9$ & $1 \cdot 8,4 \cdot 8$ & 3.5 & $2 \cdot 2,5 \cdot 6$ \\
\hline
\end{tabular}

FCS, Food Composition Score; HHFS, household food security; Ref. reference category.

*Assessed at infant age 3 months.

†Assessed at infant age 9 months.

$\ddagger$ Adjusted for socio-economic status, maternal age, literacy and parity, infant sex, district, time of enrolment and interaction between main exposure and parity. $\S$ Adjusted for socio-economic status, maternal age, literacy and parity, infant sex, district and time of enrolment.

IIDefined as $\geq 4$ meals and $\geq 4$ food groups.

Table 4 Dietary diversity comparison of 2073 mother-child dyads in 2011-2012 in Kishoreganj, Bangladesh (at child age 9 months)

\begin{tabular}{|c|c|c|c|c|c|}
\hline Food group & $\begin{array}{c}\text { Mother and child } \\
\text { ate }(\%)\end{array}$ & $\begin{array}{l}\text { Neither mother nor } \\
\text { child ate }(\%)\end{array}$ & $\begin{array}{l}\text { Mother ate, child } \\
\text { did not }(\%)\end{array}$ & $\begin{array}{l}\text { Child ate, mother } \\
\text { did not (\%) }\end{array}$ & $P$ \\
\hline Grains, roots and tubers & $92 \cdot 9$ & 0.05 & 6.9 & 0.1 & 0.20 \\
\hline Legumes and nuts & $11 \cdot 3$ & 57.8 & $25 \cdot 6$ & $5 \cdot 2$ & $<0.01$ \\
\hline Dairy products & $11 \cdot 2$ & $62 \cdot 7$ & $17 \cdot 7$ & 8.5 & $<0.01$ \\
\hline Flesh foods & $32 \cdot 2$ & 4.2 & $63 \cdot 1$ & 0.5 & $<0.01$ \\
\hline Eggs & 5.9 & 78.7 & $10 \cdot 0$ & $5 \cdot 4$ & $<0.01$ \\
\hline Vitamin A-rich fruits and vegetables & $7 \cdot 3$ & $75 \cdot 3$ & $14 \cdot 1$ & $3 \cdot 3$ & $<0.01$ \\
\hline Other fruits and vegetables & $41 \cdot 1$ & 7.9 & $49 \cdot 0$ & $2 \cdot 0$ & $<0.01$ \\
\hline
\end{tabular}

legumes and nuts (57.8\%) for both themselves and their children. We did not observe a difference between maternal and infant dietary diversity by infant sex.

\section{Discussion}

Our study assessed the association between household food security and infant feeding practices in a food-insecure population. We found that variations in household food insecurity are significantly associated with infant feeding practices in rural Bangladesh. However, maternal diet is more diverse than infant diet in our population.
To our knowledge, the present study is one of the first to use the FCS as an indicator of household food security. Developed by the World Food Programme, the validity of the FCS as a method for assessing household food security has been established ${ }^{(22)}$. Although region- or countryspecific measures to assess food security contribute to our understanding of how food security is thought of in different cultures, they make cross-country comparisons difficult to conduct. Using a more objective measure such as the FCS may assist in unbiased analyses. That both methods of assessing household food security are similarly associated with infant feeding practices in the present 
study makes it likely that the FCS is a valid measure of food security in the context of rural Bangladesh. Additional research is needed to assess whether the validity of the FCS as an indicator of food security holds in other settings.

Our study is also one of the few which looked specifically at how household food security drives infant feeding practices. The study by Saha et al. ${ }^{(25)}$ was one of the first to assess this association. Their finding that better HHFS score was associated with improved feeding practices for infants aged 6-12 months is similar to ours.

As maternal FCS is a direct measure of maternal diet, we can also conclude that maternal diet is strongly associated with infant diet. This finding is similar to those from another study conducted in Bangladesh as well research conducted in Ethiopia and Vietnam ${ }^{(26)}$. However, we also observed discordance between maternal and infant diets. For each of the seven food groups, whenever there was a discrepancy between their diets, it was in favour of the mother, meaning that even when the foods were available in the household they were not being given to the infant. This finding is in contrast to the concept of 'maternal buffering' which posits that mothers reduce their own food intake to protect their children from food scarcity ${ }^{(27)}$. Rasheed et al. ${ }^{(28)}$ observed that in Bangladesh, household knowledge regarding optimal complementary feeding practices differs substantially from international recommendations. Furthermore, cultural norms, such as advice from family members and the importance of feeding young children, also influence complementary feeding practices. Understanding the cultural context that determines infant diet and feeding will be critical in improving infant feeding practices, and thus nutrition, in this setting.

The amount of schooling completed by mothers is highly associated with improved child health, diet and nutritional outcomes, especially in low-income settings ${ }^{(26,29-32)}$. Therefore, it is surprising that this association does not hold in our study. This finding may be an indication that improved maternal literacy does not translate directly to better child-rearing practices in rural Bangladesh and that interventions for improved child growth and survival in this setting need to be multi-factorial.

A major strength of our study is the large sample size which increases the power of analyses. Furthermore, as this was a prospective cohort study, the main exposure was assessed prior to the outcome. This strengthens our ability to make causal inferences. However, as with any other observational study, this one also has some limitations. First, both the outcome and exposure measures are based on maternal recall of what she and her child ate. However, the time lag between dietary intake and report is comparatively small: $7 \mathrm{~d}$ in the case of the mother and only $24 \mathrm{~h}$ for the infant. We also could not explore why mothers would not give specific foods to infants. This is an important avenue for future research in identifying barriers to optimal complementary feeding practices in Bangladesh.

\section{Conclusion}

The present study adds to the body of evidence on how household food security is related to infant feeding practices in low-income settings. We observed that more food-secure households employ improved infant feeding practices. Our findings imply that interventions aimed at improving infant nutritional status need to focus on both complementary food provision and education.

\section{Acknowledgements}

Financial support: This study was supported by grants from CARE USA to Emory University and the International Centre for Diarrheal Disease Research, Bangladesh (icddr,b). The funders had no role in the design, analysis or writing of this article. The authors have no relevant financial relationships to disclose. Conflict of interest: None. Authorship: A.D.S., A.S.G.F. and B.S. designed the cohort study. A.S.G.F. and S.K.D. led field activities and supervised data collection. A.O., D.G.K., P.S.S., B.S. and A.D.S. conceived and planned the data analysis. A.O. analysed the data. A.O. and A.D.S. wrote the manuscript. All authors critically reviewed the manuscript and approved the final version. Ethics of human subject participation: This study was approved by the Research Review Committee and the Ethical Review Committee of icddr,b. At the time of enrolment, informed consent was provided by each participant. Verbal consent, witnessed and formally recorded, was obtained at each follow-up visit.

\section{References}

1. Cai X, Wardlaw T \& Brown DW (2012) Global trends in exclusive breastfeeding. Int Breastfeed J 7, 12.

2. World Health Organization (2002) Infant and Young Child Nutrition: Global Strategy on Infant and Young Child Feeding. Geneva: WHO.

3. Bhutta ZA, Ahmed T, Black RE et al. (2008) What works? Interventions for maternal and child undernutrition and survival. Lancet 371, 417-440.

4. World Health Organization (2003) Global Strategy for Infant and Young Child Feeding. Geneva: WHO.

5. Walker CL, Rudan I, Liu L et al. (2013) Global burden of childhood pneumonia and diarrhoea. Lancet 381, 1405-1416.

6. Bhutta ZA \& Salam RA (2012) Global nutrition epidemiology and trends. Ann Nutr Metab 61, Suppl. 1, 19-27.

7. Bryce J, Coitinho D, Darnton-Hill I et al. (2008) Maternal and child undernutrition: effective action at national level. Lancet 371, 510-526.

8. National Institute of Population Research and Training, Mitra and Associates \& Macro International (2013) Bangladesh Demographic and Health Survey 2011. Dhaka and Calverton, MD: NIPORT, Mitra and Associates, and Macro International. 
9. Kabir I, Khanam M, Agho KE et al. (2012) Determinants of inappropriate complementary feeding practices in infant and young children in Bangladesh: secondary data analysis of Demographic Health Survey 2007. Matern Child Nutr 8 , Suppl. 1, 11-27.

10. World Health Organization (2014) Food Security. http:// www.who.int/trade/glossary/story028/en/ (accessed October 2014).

11. Black RE, Allen LH, Bhutta ZA et al. (2008) Maternal and child undernutrition: global and regional exposures and health consequences. Lancet 371, 243-260.

12. Black RE, Victora CG, Walker SP et al. (2013) Maternal and child undernutrition and overweight in low-income and middle-income countries. Lancet 382, 427-451.

13. Kirk SF, Kuhle S, McIsaac JL et al. (2015) Food security status among grade 5 students in Nova Scotia, Canada and its association with health outcomes. Public Health Nutr $\mathbf{1 8}$ 2943-2951.

14. Stuff JE, Casey PH, Szeto KL et al. (2004) Household food insecurity is associated with adult health status. J Nutr 134, 2330-2335.

15. Singh A, Singh A \& Ram F (2014) Household food insecurity and nutritional status of children and women in Nepal. Food Nutr Bull 35, 3-11.

16. Leung CW, Epel ES, Ritchie LD et al. (2014) Food insecurity is inversely associated with diet quality of lower-income adults. I Acad Nutr Diet 114, 1943-1953.

17. Vozoris NT \& Tarasuk VS (2003) Household food insufficiency is associated with poorer health. J Nutr 133, 120-126.

18. Lassi ZS, Das JK, Zahid G et al. (2013) Impact of education and provision of complementary feeding on growth and morbidity in children less than 2 years of age in developing countries: a systematic review. BMC Public Health 13, Suppl. 3, S13.

19. Thomas JS, Yu EA, Tirmizi N et al. (2014) Maternal knowledge, attitudes and self-efficacy in relation to intention to exclusively breastfeed among pregnant women in rural Bangladesh. Matern Child Health J 19, 49-57.

20. Yu EA, Thomas JS, Owais A et al. (2015) Maternal prenatal attitudes and postnatal breast-feeding behaviours in rural Bangladesh. Public Health Nutr 18, 679-685.

21. World Health Organization (2010) Indicators for Assessing Infant and Young Child Feeding Practices. Part 2: Measurements. Geneva: WHO.
22. Wiesmann D, Basset L, Benson T et al. (2009) Validation of the World Food Programme's Food Consumption Score and Alternative Indicators of Housebold Food Security. Washington, DC: International Food Policy Research Institute.

23. Frongillo EA, Chowdhury N, Ekstrom EC et al. (2003) Understanding the experience of household food insecurity in rural Bangladesh leads to a measure different from that used in other countries. J Nutr 133, 4158-4162.

24. Filmer D \& Pritchett LH (2001) Estimating wealth effects without expenditure data - or tears: an application to educational enrollments in states of India. Demography 38, $115-132$.

25. Saha KK, Frongillo EA, Alam DS et al. (2008) Household food security is associated with infant feeding practices in rural Bangladesh. J Nutr 138, 1383-1390.

26. Nguyen PH, Avula R, Ruel MT et al. (2013) Maternal and child dietary diversity are associated in Bangladesh, Vietnam, and Ethiopia. J Nutr 143, 1176-1183.

27. Coates J, Frongillo EA, Rogers BL et al. (2006) Commonalities in the experience of household food insecurity across cultures: what are measures missing? J Nutr 136, issue 4, 1438S-1448S

28. Rasheed S, Haider R, Hassan N et al. (2011) Why does nutrition deteriorate rapidly among children under 2 years of age? Using qualitative methods to understand community perspectives on complementary feeding practices in Bangladesh. Food Nutr Bull 32, 192-200.

29. Smith-Greenaway E (2013) Maternal reading skills and child mortality in Nigeria: a reassessment of why education matters. Demography 50, 1551-1561.

30. LeVine AR, LeVine S, Schnell-Anzola B et al.. (2012) Literacy and Mothering: How Women's Schooling Changes the Lives of the World's Children, Child Development in Cultural Context. New York: Oxford University Press.

31. Janevic T, Petrovic O, Bjelic I et al. (2010) Risk factors for childhood malnutrition in Roma settlements in Serbia. BMC Public Health 10, 509.

32. Meshram II, Kodavanti MR, Chitty GR et al. (2013) Influence of feeding practices and associated factors on the nutritional status of infants in rural areas of Madhya Pradesh State, India. Asia Pac J Public Health 27, NP1345-NP1361. 